\title{
Is 'recognition' in the sense of intrinsic motivational altruism necessary for pre- linguistic communicative pointing?
}

\author{
Heikki Ikaheimo (heikki.ikaheimo@mq.edu.au) \\ Department of Philosophy, Macquarie University \\ New South Wales 2109, Australia \\ Forthcoming in Wayne Christensen, Elizabeth Schier, John Sutton (ed.): ASCS09: Proceedings of the
Australasian Society for Cognitive Science. Sydney: Macquarie Centre for Cognitive Science, 2010.
}

\begin{abstract}
The concept of recognition (Anerkennung in German) has been in the center of intensive interest and debate for some time in social and political philosophy, as well as in Hegelscholarship. The first part of the article clarifies conceptually what recognition in the relevant sense arguably is. The second part explores one possible route for arguing that the 'recognitive attitudes' of respect and love have a necessary role in the coming about of the psychological capacities distinctive of persons. More exactly, it explores the possibility that they are necessary in the kind of intersubjective relationship in which normal human infants engage in the pre-linguistic communicative practice of pointing things to others, as described by Michael Tomasello. If an incapacity to participate in the already Gricean communicative practices of pointing makes it also impossible for the infant to learn symbolic communication, and if without the immediately intrinsically motivating otherregarding attitudes of recognition communicative pointing does not get off the ground (at least among the most intelligent animals currently known to exist), then the capacity for recognition may be a decisive difference between humans and their closest non-human relatives. That is, it may be why only human infants, but no other animals, are capable of embarking on a developmental journey that normally leads to full-fledged psychological personhood. If this is so, then the concept of recognition, today mostly discussed in social and political philosophy and Hegelstudies, could turn out to be a very useful tool in cognitive scientific work interested in specifically human forms of social intentionality, cognition, volition and so forth.
\end{abstract}

Keywords: altruism; helping; personhood; pointing; recognition.

\section{Recognition as an ethical and ontological concept}

The aim of this paper is to bring together two discussions: on the one hand the discussion on the concept of recognition (Anerkennung) in social and political philosophy and Hegelscholarship, and on the other hand the discussion on communicative pointing in primatology and evolutionary anthropology. The aim is to clarify what exact role intersubjective attitudes of recognition have in the development of specifically human forms of social intentionality, cognition, volition and so forth.

The concept of recognition (or Anerkennung in German) has been in the center of intensive interest and debate for some time in social and political philosophy, ${ }^{1}$ as well as in Hegel-scholarship. ${ }^{2}$ It is widely agreed that recognition is, as Charles Taylor $(1992,26)$ puts it, "a vital human need", that lack of adequate recognition can be a serious problem in human relationship, and that social and political demands and struggles are often about recognition between individuals or groups. But what exactly is recognition in the relevant sense? $?^{3}$

When discussing the theme in English, one needs to distinguish, to start with, between three different meanings of the word 'recognition'. First, there is 'recognition' in a sense in which it is synonymous with 'identification'. In this sense one can recognize, i.e. identify anything generically, qualitatively or numerically (say, as a face, as a friendly face, or as John's face, respectively).

Secondly, there is 'recognition' in a sense in which it is, at least roughly, synonymous with 'acknowledgement'. We acknowledge norms, institutions, statuses, principles, rules and claims as binding, valid or legitimate, reasons as good, values as genuine, facts as licensing or forcing conclusions with other facts, something as giving reasons, as valuable, or the case, and so forth.

Thirdly, whereas anything can be identified, and whereas only normative or evaluative entities can be acknowledged, there is a sense of the word 'recognition' in which it is appropriate to recognize only persons.

Even if all three senses of 'recognition' are no doubt in many ways interrelated, and even if especially the first and the third sense are often indiscriminately confused with each other in political and social philosophy, the directly relevant sense is the third one. But what is recognition in this sense.

\footnotetext{
${ }^{1}$ See Thompson 2006; van den Brink \& Owen 2007; Schmidt am Busch \& Zurn (forthcoming).

${ }^{2}$ See Siep 1979; Wildt 1982; Honneth 1995; Williams 1992 and 1997.

${ }^{3}$ Details of the view on recognition and personhood presented in this paper are discussed in Ikaheimo 2007, Ikaheimo 2010 and Ikaheimo \& Laitinen 2007.
} 
Looking at the debates, pretty much everyone agrees, explicitly or implicitly, that recognition is some kind of an affirming attitudinal response to persons or groups of persons. In other words, it is, at least implicitly, agreed that to have recognition towards others is to have some kind of practical, and somehow affirmative, attitudes towards them.

We may draw closer to a definition of recognition in the relevant sense by taking a look at what recognition is thought to $d o$. Here there are basically two kinds of views present in the discussions. On the one hand there are qualitative views, widespread in social and political philosophy, according to which recognition changes what it affects by changing its qualities - and as a rule changing them for the better. Thus, it is thought that being the object of recognition by others is good for a person's psychological life, his self-identity, self-relations, and psychological resources for self-realization and so forth. It is also widely thought that recognition between individuals and groups is in various ways good for the quality of social or political life. In principle 'goodness' can be understood here in a functional, or in an ethical sense, or both. Thus, it can be argued either that more recognition makes functionally better individuals and/or societies, or that it makes ethically better individuals and/or societies, or both.

On the other hand, there are ontological views, put forth by a number of contemporary neo-Hegelian philosophers like Robert Brandom, according to which recognition makes what it affects the kinds of beings they are. Namely, it distinguishes $u s$ and our 'spiritual' life-form from mere animals and their natural life-form. I believe we can usefully translate this view by saying that according to it recognition is essential in what is distinctive of persons and their lifeform.

But is there a way to conceive of both the qualitative and the ontological views as talking of the same thing? Or to put this in another way, is there really some phenomenon called 'recognition' that could do both jobs - both make our lives as persons (individually and/or collectively, functionally and/or ethically) better, and make us psychological persons in the first place. I take it that according to Hegel's original idea recognition is such a phenomenon, and even if Hegel himself never gave anything like a simple definition of recognition that would make it immediately clear how exactly this could be so, we can explicate the concept so that it does make good sense. According to the explication attitudes of recognition are attitudes of taking something/one as a person. But what exactly is it to take something/one as a person in this Hegelian sense of recognizing it/her?

There are two candidates, both of which, I suggest, are species of the genus 'recognitive attitude'. One of these is central to Robert Brandom's neo-Hegelian theory of semantic norms. In Brandom's (1999) view, to recognize someone is to take her as having authority on one. The point is that mutually taking others as having authority on one's conceptual grasp of the world is constitutive of the space of semantic norms, or of the collectively administered ways of carving up the world in linguistically informed thought and perception. The details of Brandom's account are not important here, but only the general idea about the necessary connection of shared or 'social' norms on the one hand, and mutually taking others as having authority, and thereby sharing authority, on the other hand.

It is arguably carving reality at a very important joint to say that persons differ from mere animals (i.e. those animal that are not persons psychologically) in that the former are governed by social norms. On this view the capacity to participate in the administration of social norms is the person-making psychological capacity (quite obviously it is a cluster of capacities) and this necessarily involves the capacity to take others as having authority on one, or as sharing authority with one. No-one can be governed by social norms without being moved by their authority on one, which on this analysis boils down to the authority of the relevant other subjects. And the others' having authority on one requires that one takes them as authorities on oneself. On the other hand, one can share authority with others, and thus participate in the administration of social norms only if the others take one as having authority on them. Taking something/-one as having authority on one is thus here what it means to take something/-one as a person, i.e. to have a practical attitude of recognition towards it/her; and the practical and hence motivating or 'moving' significance of 'an authority' is the corresponding practical person-making significance in light of which persons see each other.

From Hegel's point of view this however is only half of the story of the role of recognition in our being spiritual beings, or in other words of the role of taking others as persons in personhood. What is absent from Brandom's story is whatever it is that Hegel has in mind when he talks of love as a form of recognition. ${ }^{4}$ On the full Hegelian picture, or my construal of it, recognition in Brandom's sense - let us call it respect - and recognition as love are two species of the genus recognitive attitude, or two ways of taking something/-one as a person. ${ }^{5}$ But if respect as a way of taking something/-one as a person is taking it/him as having authority on one, what is love as a way of taking something/-one as a person? I believe the best way to make sense of this is to explicate love as the attitude of taking something's/someone's well-being or happiness as intrinsically important, or in short taking something/-one as an end in herself. Analogically to respect, this is not primarily a matter of having beliefs about the object, but of being 'moved' by her - a volitional response of caring

\footnotetext{
${ }^{4}$ See Hegel 1978-9, § 436. To be exact, Brandom's view arguably also lacks a robust sense of recognition transforming the recognizer's basic motivations and thus of what I mean by a 'volitional response' (see note 6). See Brandom 2007, where all the motivational work in recognition is apparently done by desire. In presenting Brandom's theory as an example of the view I am proposing, I am thus idealizing it somewhat.

5 The idea that recognition has several types or species comes from Honneth 1995.
} 
intrinsically or non-instrumentally. ${ }^{6}$ And analogically to the practical significance of 'authority' attributed by the recognitive attitude of respect, the practical significance attributed by the recognitive attitude of love is something like an 'end in herself', or 'someone whose well-being or happiness is intrinsically important'.

Now, love is no doubt in many ways good for persons, but isn't it exaggerated to say that it is constitutive of their being persons in the first place? I do not think so. The idea of self-love in the sense of intrinsic concern about one's own well-being or happiness as being constitutive of personhood can be found in various versions throughout the history of philosophy from Aristotle, through John Locke to Harry Frankfurt. Roughly, the idea is that whereas mere animals are moved by desires or other immediately motivating states, persons are moved by self-regarding concerns that transcend the immediately given and maximally encompass the goodness of one's life as a whole. It is really not much more scandalous to claim that the capacity to love also (at least some) others in this sense is part of what constitutes the psychological capacities of full-fledged personhood. Clearly at least a complete incapacity to be intrinsically concerned about the well-being, happiness or goodness of life of any other people is considered as a serious deficiency of personhood. And arguably being taken by others as an end in oneself, or in other words as someone whose subjective well-being or happiness is intrinsically important, is as important an element of having the interpersonal status of a person in concrete social contexts as is being taken by others as someone who has authority on them. ${ }^{7}$ One may doubt whether it is even possible to take someone as having normative authority on one while at the same time not seeing her well-being or happiness as having any intrinsic importance.

As to the question whether recognition in the two senses of respect and love can do both jobs mentioned above - both make us persons in the first place, and make our lives better in various ways - the answer is, I suggest, affirmative. As to the ontological perspective, not only can they be seen as constitutive of what it is to be a person in the above laid out sense, it is clearly also causally important for the normal development of the psychological person-making capacities that one is taken as a person by others in the ways of respect and love. And from the qualitative point of view, it is not difficult to defend the claim that within the life-form of persons (as we know it as participants in it), as a rule, more mutual respect and mutual intrinsic concern makes up functionally better (harmonious, stable etc.) psychological and social life, nor is it very difficult to defend the claim

\footnotetext{
${ }^{6}$ By 'volitional response' I mean a response to something given that transforms the responder's basic motivations. In brief: on my account the attitudes of recognition - both respect and love - are motivational states that transcend the immediate animal motivations such as immediate desires for something given.

${ }^{7}$ On the relation of psychological personhood to interpersonal and institutional statuses of a person, see Ikäheimo 2007.
}

that more of them makes, as a rule, ethically better persons and collectives.

But how strong a claim can one plausibly make regarding the importance of recognition in the development of the normal psychological makeup of a person? In what follows, I will briefly explore the possibility that the recognitive attitudes of respect and love have an empirically necessary role in the human infant's entering into relationships of prelinguistic triadic communication - namely into the cooperative practice of pointing things to others.

\section{Recognitive attitudes in communicative pointing}

The primatologist and anthropologist Michael Tomasello, with his research group at the Max Planck Institute of Evolutionary Anthropology in Leipzig, has recently done extensive research on the pre-linguistic triadic communicative practice of pointing things to others (paradigmatically with the index-finger). According to Tomasello (2006, 507), there is not one single reliable observation of a chimpanzee or any other ape ever having pointed anything to another ape. Nor do chimpanzees seem to understand humans pointing things to them. In contrast, normal human infants at around their first birthday are able to understand others pointing to them as well as able to point things to others (507-8). Pointing is a significant phenomenon since it is a way of intentionally creating triadic structures of joint reference, and thereby becoming to attend the world in ways that are shared and jointly controllable. There is good reason to believe that this provides an important background for the practice of symbolic communication and thereby for the further development of cognitive capacities that distinguish humans from those animals that lack symbolic communication (see Moll 2007).

Criticizing and elaborating on the classic view on the different forms of pointing (Bates et al., 1975), Tomasello claims that there are three basic forms of, or proto-speech acts performed in infant pointing: 'requesting', 'informing' and 'sharing' (Tomasello 2008, 83-8; see also Liszkowski 2006). A paradigmatic case of requesting by pointing is when an infant points something to an adult with the intent that the adult would give it to her. A paradigmatic case of informing is when an infant points something to an adult that the infant believes is interesting or useful to the adult. In sharing by pointing the infant wants to share emotions or attitudes about an object with the addressee. In what follows, I will mostly focus on requesting and say briefly something about informing towards the end. What is common to both of these proto-speech acts is the phenomenon of helping: requesting is requesting the other to help, and informing is offering help.

Why is it that our closest non-human relatives apparently neither point things to each other, nor understand when humans try to point something to them? They certainly do not lack the rather simple motor skill to extend their arm and index-finger to point at something. As to their cognitive 
capacities, on Tomasello's view they also do not lack the capacity to grasp others as intentional beings and interpret the directedness of their intentionality. In other words, they do have capacities of mind-reading enabling them to understand what another ape or human perceives or aims at in familiar enough situations (Tomasello 2006, 506-7; Tomasello 2008, 176-7; Moll 2007, 38-40). One possibility is that they lack the more demanding capacity of recursive mind-reading (reading the other reading one's mind, reading the other reading one reading her mind, and so forth, Tomasello 2008, 321, 335-7). But importantly, even if chimpanzees would have this capacity - which in principle makes it possible for one to grasp that the other intends to affect one's mind by pointing, as well as makes it possible to grasp the possibility of affecting the other's mind by pointing so that she knows one is trying to do this (which is what Tomasello calls "Gricean communication" after Grice 1957) - communicative pointing could not exists as a practice among them if they lacked appropriate motivations and expectations concerning each other's motivations. That is, in order to get the practice of pointing off the ground - at least in the requesting and informing modes - subjects need to have motivations to help, as well as expect each other to have such motivation. Is this something chimpanzees lack, as Tomasello suggests $(2006,516)$ ?

One way to formulate the question is to ask whether chimpanzees lack motivation to act in ways that are altruistic and/or expectations that others would act altruistically. But we need conceptual caution here. First, one needs to distinguish between behavioral and motivational (or psychological) senses of 'altruism'. ${ }^{8}$ In the behavioral sense altruism is a property of behavior attributed regardless of what motivates the behavior: in this view altruistic behavior is simply behavior of $\mathrm{A}$ that is beneficial to $\mathrm{B}$, regardless of whether $\mathrm{A}$ wants to benefit $\mathrm{B}$. In the motivational sense altruism is a property of motivation: Altruistic motivation is motivation of $\mathrm{A}$ to behave or act in a way that $\mathrm{A}$ conceives as beneficial to $\mathrm{B}$ and costly to herself. On this concept also behavior or action is altruistic only if it is motivated by altruistic motives. ${ }^{9}$

Secondly, the motivational concept of altruism still allows for a looser and stricter variant. On the looser concept motivation is altruistic regardless of whether it is conditional on the subject conceiving the costs to herself as an investment for some (often future) gain to itself, or not. Some investment-considerations are involved in all instrumental action: the agent aims at some goal that she sees worthwhile and will choose means or instruments whose costs in her view do not outweigh the benefits of the goal. Thus, A may be motivated to help B since A believes this will increase the likelihood of $\mathrm{B}$, or some others,

\footnotetext{
${ }^{8}$ See Dixon 2005. There is also normative or ethical altruism in contrast to normative or ethical egoism, but this need not concern us here.

9 Thus when for example Jesse Prinz (2007, 247) notes that "[a]1truistic behavior is everywhere in nature", he uses "altruism" in the behavioral, not motivational sense.
}

helping her when needed, and estimates that the benefit of this likelihood outweigh the costs incurred by helping B. Let us call this instrumental motivational altruism.

On the stricter concept however, this is not an altruistic but on the contrary an egoistic motive to help the other. It is helping because of an expected gain to oneself. In contrast, a genuinely altruistic motive to help on the stricter concept is one that is not conditional on expected gain to oneself. Such a motive to help is non-instrumental in the sense that the good of the other (or the helping behavior) ${ }^{10}$ is not merely instrumentally valuable for the helper in light of the further end of benefit to herself. On the contrary, it is intrinsically valuable for her and thus provides an intrinsic motivation to help; in other words, it provides a motivation that is 'immediate' in the sense of not derived from any further end. Let us call this intrinsic motivational altruism.

Assuming that one observes apparently altruistic behavior among animals or humans, the first question from a philosophical point of view is whether what is at issue is merely behavioral altruism, or motivational altruism; and if it is motivational altruism, whether it is instrumental or intrinsic motivational altruism. Also, if one interprets what one observes as helping, it is important to be clear on which exact concept of helping. In the loosest (causal) sense of the word sun and rain help plants to grow. Secondly, in still a rather loose (behavioral) sense animals help other animals when they behave in ways that are advantageous to the others, or in other words when their behavior is altruistic in the behavioral sense. But thirdly, on what is clearly the intuitively default sense of the word, 'helping' is a term for intentional action where the helper intends her action to result in something advantageous to the other. If this is the case, one still needs to ask whether the helper's motives are instrumentally or intrinsically altruistic. ${ }^{11}$

An interesting question is whether instrumental motivational altruism and expectations about others being instrumentally altruistic would be enough to get and keep practices of requestive and informative pointing going, or whether (some degree of) intrinsically altruist motivation is necessarily required? If the latter would turn out to be the case, this could help in sharpening the focus on the question why apes do not point (compare Tomasello 2006, 516), but human infants do. ${ }^{12}$ One could allow the possibility that

\footnotetext{
${ }^{10}$ Note that if the helper's end is benefit to herself, then sometimes even feigning to help may be enough, since this may trigger reciprocation. Thus, there can be cases where a subject shows 'helping behavior' in expectation of reciprocation without aiming at benefiting the other at all.

${ }^{11}$ Compare Joyce (2006, 13-14), who defines altruism according to what I mean by intrinsic motivational altruism, but helping behaviorally as "behaving in a way that benefits another individual".

${ }^{12}$ In fact, captive chimpanzees are able to learn some behavior that resembles pointing, which however most probably does not have a communicative structure of a kind described below (Tomasello 2006, 507). Compare Leavens et al. (2008) who defend the thesis that captive apes sometimes engage in "whole hand pointing" to humans, but who apparently do not grasp the difference between
} 
apes have instrumentally altruistic motives (and therefore be free of the burden of proof that they do not), while focusing on the hypothesis that they lack intrinsically altruistic motives and that this may be part of the explanation why they never engage in requestive or informative pointing. ${ }^{13}$

In what follows, I will present some considerations in support of the hypothesis that intrinsic altruism is necessary for requestive and informative pointing. Minimally, I want to show that whether it is is a genuine question with consequences as to the proper way of thinking about the requirements and structure of these forms of pointing. Let me first elaborate a bit more on the concept of intrinsic motivational altruism. Above I have given a rather conventional explication of the concept of altruism where what I called intrinsic motivational altruism is wanting to do something that one thinks is good for the other out of intrinsic concern for her good. But in fact I believe that the wealth of intuitions that authors have tried to grasp with the concept of altruism would be better served by distinguishing between two phenomena.

One is having an immediate or non-instrumental motivation to benefit the other, or in other words being immediately 'moved' by something like the claim of her good, well-being or happiness. The other is an immediate or non-instrumental motivation to satisfy her will, or in other words being immediately 'moved' by a claim of authority of hers on one. To give an illustration: the one is at stake when one is non-instrumentally motivated by someone's request or petition for something with the tone "please" or "I beg you", whereas the other is at stake when one is noninstrumentally motivated by someone's request or petition for something with the tone "you ought to" or "I command you".

Both are genuinely or ultimately other-regarding, or alter-istic motivational responses in that in neither does the motivation stem from some further consideration external to the simple 'claim' that the other person, or confronting the other person, makes on one. The first is the 'axiological' species of intrinsic motivational altruism, and is what I mean by love as a recognitive attitude; the second is the 'deontological' species of intrinsic motivational altruism and is what I mean by respect as a recognitive attitude. With the risk of some intellectual muscle ache incurred by straining intuitions habitualized by the standard association of altruism with love and other axiological phenomena, I suggest a revision to the meaning of 'altruism', or to be exact 'intrinsic motivational altruism' so that it includes both of these genuinely or ultimately other-regarding motives or volitional responses. In other words, intrinsic motivational altruism' is synonymous with 'recognitive

trying to affect others through their mind (which is what captive apes seem to be doing) and trying to affect others communicatively (which is what Tomasello primarily means by 'pointing').

${ }^{13}$ Tomasello $(2008,37)$ suggests that "apes are not motivated to help [...] in the same way as humans" (emphasis H.I.), but does not say what is the way in question. I suggest that it is helping out of intrinsically altruistic motives. attitude', and these name a genus the species of which are love and respect.

Now, the idea that recognitive attitudes are either necessary or at least very important for the normal development of a healthy human psyche plays an important role in contemporary discussions on recognition in social and political philosophy. ${ }^{14}$ But the devil is always in the details: what exactly is it that one means by 'recognition' and which exact role in what exactly in the human ontogenesis one is claiming it has? Let us accept the definitions for recognition cum intrinsic altruism in the forms of love and respect given above, and let us focus on the question what role they might have in the coming about of requestive and informative pointing in infants. Let me cite Tomasello's rendering of an interesting experiment by Helen Schwe and Ellen Markman.

[...] Schwe and Markman (1997) had an adult respond to the request of two-year-olds by, among other things, refusing them or misunderstanding them. When the child's request was refused she was not happy and displayed this in various ways. But when her request was misunderstood - even in cases in which the adult actually gave her what she wanted unintentionally ("You want this (wrong object)? You can't have it but you can have this one (right object) instead.") - the child was not fully satisfied and often repeated her request. Under this [Tomasello's, H.I.] interpretation, infants from a certain age are pointing imperatively not as a blind procedure for making things happen, but as a request that the adult know her goal and decide to help her attain it. (Tomasello 2006, 511-512)

Tomasello takes this description as revealing of the structure of full-fledged requestive pointing in children, which in his view is not merely an attempt to influence the other's behavior through her mind, but an attempt to influence her behavior through her mind by letting her know that one is trying to influence it. Thus, it has a roughly Gricean communicative structure involving something like "I want you to know that I want something from you" (Tomasello 2008, 88). Tomasello interprets this in terms of the child "informing the adult of [one's] desire" so that the adult would "agree to cooperate" (123) or "decide to help [one] fulfill it" (84). According to Tomasello this is not "ordering" the other, which he interprets as the mere attempt to causally influence the other through her mind - something apes may do with their 'warning' signals (84).

I believe Tomasello is mistakenly identifying here two different distinctions. First of these is between, on the one hand, attempting to influence others causally through their minds ("getting others do what one wants them to" (84)), and, on the other hand, attempting to influence them communicatively (letting them know that one wants them to

\footnotetext{
${ }^{14}$ Especially important in this regard are Honneth 1995 (chapters 4 \& 5), and Honneth 2008, 40-52.
} 
do something by making it overt that this is what one is trying to do). ${ }^{15}$ The second distinction is between, on the one hand, "ordering", and, on the other hand, what Tomasello calls communicatively "informing" the other of one's "desire".

Contrary to what Tomasello suggests, "ordering", at least in the default sense of the word, is clearly not a mere attempt to influence the other causally through her mind (like, say, screaming so that the other would feel an immediate urge to flee), but as much a communicative act as communicatively informing the other of one's desire is. Consequently, we need to divide the general communicative act of 'requesting' into two species and distinguish both from not genuinely communicative ways to affect the minds of others by signals. Accordingly, there are two different communicative intentions that may be at issue in the experiment by Schwe and Markman.

In both cases the child wants that the adult's motivation to help stems from what the child is trying to communicate to her - and this is why she is not satisfied when the adult gives her the right object, yet apparently with some other motivation. But what exactly it is that the child is trying to communicate can in principle be either her need, or her will. (Of course it can be both, but let us focus on the pure cases to grasp the contrast clearly.) In the first form of request I want that your motivation to give me that thing stems from my needing it. In the second form of request I want that your motivation to give me that thing stems from my wanting that you do so. Let us call the first form of request appeal and the second form command.

Notice now that in both forms an action by the addressee that satisfies the request must be motivated by what the addressor tries to communicate - either her need or her will - but that in both cases this still leaves open whether the motivation can or must stem from this mediately or immediately, or in other words whether it can or must be instrumental or intrinsic motivation. One may be motivated to satisfy the need of the other and thus to support her wellbeing either because her well-being is likely to be somehow beneficial to oneself (or third persons one cares about intrinsically), or by the immediate, non-instrumental volitional response of concern for her well-being, or love that is. Analogously, one may be motivated to satisfy the will of the other either because obeying her is likely to be beneficial to oneself (or third persons) in some way (and resisting perhaps harmful), or by the immediate, noninstrumental volitional response to her as having some authority on one, or respect that is. ${ }^{16}$

\footnotetext{
15 There is also an intermediate form, which is attempting to influence others by letting them know that one wants them to do something without making it overt that this is what one is trying to do. See Tomasello 2008, 90.

16 Note that I mean 'authority' here in an emphatically interpersonal sense, independent of institutional positions or powers that give people various kinds of institutionally enforced claims or institutionally backed 'authority'.
}

The central question for my purposes is whether the child expects that the adult be intrinsically motivated by what she is communicating - or in other words motivated by recognition in the sense of respect and/or love for her. To answer the question empirically one would need to device experiments premised on the distinctions made above between the axiological dimension of need, well-being and so on, and the deontological dimension of will, authority and so on, as well as between instrumental and intrinsic motives on both dimension. In lack of such experiments, or at least my knowledge of them, I will continue in the philosopher's armchair and rephrase the question: does a child at two years expect that the adult responds to her requestive pointing out of recognition for her (in the exact sense spelled out above), or in other words, does she interpret the adult's response as revealing either recognition or lack of it? It is clear that instrumental motives are ubiquitous in everyday communication, and thus if children would expect adults to be completely devoid of them, they would be seriously out of touch with reality. But of course they can't be, lest they are to develop a highly dysfunctional relation to others. The question is thus whether the adult's apparently having only instrumental motives would satisfy the infant's request made by requestive pointing. This is a question not to be settled by philosophers but by empirical research.

Importantly, according to Tomasello there is not enough evidence to warrant an attribution of a fully (Gricean) communicative structure to infant pointing right from the beginning, that is, at around the first birthday (2008, 144). Hence we are perhaps also not warranted to attribute much in the way of distinctiveness in the expectations that infants have with regard to the adult's motivations when they start pointing things to them at 12 months. A year later however children are apparently capable of distinguishing at least between a response to requestive pointing motivated by the content of a request and a response otherwise motivated - as the experiment by Schwe and Markman shows. But can they distinguish between instrumental and intrinsic motivation by the content of the request?

If one accepts that the concept of love, as explicated above, applies anywhere in reality, then the least controversial claim is certainly that it applies in the typical relations of human parents to their children. We expect that parents love their children in the sense that they have (also) intrinsic concern for their well-being and happiness, and we think that this is the case in non-pathological parent-childrelationships. I assume that we are right to do so. As to respect, there is an analogical claim to be made. Any rule or norm governing interaction is indeterminate in the sense of requiring specification in its application to concrete cases. That the content of norms is specified in application means that anyone acting on norms has some authority on them. Consequently, there is practically nothing children can learn from adults that would not require an active effort of interpretation and application by the child, and thereby some 
amount of her sharing authority with the adult. ${ }^{17}$ This is as true of semantic norms as it is of good manners or moral norms. To the extent that parents manage to teach their children anything, or interact with them in ways from which the infant can learn almost anything at all, they have to acknowledge this truth in the way that they interact with their children. Further, it seems extremely unlikely that such interaction would be fluent and thus well-functioning without at least a significant part of the adult's acceptance of the child's claim for authority being immediate or noninstrumental. In other words, due to the ontology of normgoverned interaction parents have to have at least some noninstrumental acknowledgement or acceptance of the child's authority, or in other words some respect for the child.

Arguably then, it is part of the normal social environment of the developing human infant that caretakers act with regard to them out of at least some intrinsically altruistic motivation, or at least partly out of love and respect that is. Thus, by the time infants become capable of discerning between different relevant motivations of others - whether this is at 12 months, 24 months, or somewhere in between it should be part of their default horizon of expectations that they are objects of these intrinsic motives. Therefore it would not be surprising if it would turn out that at this point they normally expect others to have intrinsic motives to respond to their requestive pointing: in requestive pointing of the 'appealing' sub-type intrinsic concern for the child's needs and well-being, and in requestive pointing of the 'commanding' sub-type intrinsic acknowledgement of the child's authority. ${ }^{18}$

Of course other possibilities cannot be ruled out a priori. First, there is the possibility, even if intuitively a rather unlikely one, that infants expect that the relevant others have also intrinsically altruistic motives, yet respond to requestive pointing for instrumental motives. Secondly, there is the intuitively perhaps less unlikely possibility that infants expect that others respond to their requestive pointing sometimes for intrinsically, other times for instrumentally altruistic motives; and, thirdly, that they expect that others usually respond for mixed motives. However, there is at least one consideration that speaks for attributing intrinsically altruistic motives a necessary role in infant pointing.

Requestive pointing is generally speaking a cognitively highly demanding practice. Add to this a need to estimate whether the other is instrumentally motivated to do

\footnotetext{
17 This is emphasized in a very illuminating way by Pirmin Stekeler-Weithofer (2007 and (forthcoming)).

${ }^{18} \mathrm{I}$ assume here that respect for the other as having authority on norms, and respect for the other as issuer of commands are instances of the same phenomenon, which is that of being intrinsically moved by the will of the other. My hypothesis is that participation in communication, requiring at least some minimal amount of respect for the other as sharing authority on norms with oneself, thus prepares one to experiencing the 'commanding requests' by the other as motivating. Whether action follows of course depends on the subject's total motivational set.
}

something one wants her to do, whether there is a gain for the other in helping that would be motivating for her, or what is it that the other might expect in return as a prize for her instrumental altruism. That is, add to the other cognitive requirements of requestive pointing (most importantly recursive mind-reading) the requirement to deliberate on chains of instrumental reasons that the other may, or may not, have - and you may have set a task cognitively so demanding that learning its execution is simply too difficult for any existing species of animals. ${ }^{19}$

So here's the proposal. Perhaps a decisive privilege that human children have over their ape relatives is that they are free of the burden of having to consider their relevant others' instrumental motives in everything they do with them, and can often simply rely on their being motivated to respond positively to one's needs or will immediately, regardless of instrumental considerations.

And whatever the developmental details, perhaps this is also the default way in which the normal human child responds to the requestive pointing of others, as well as the child's default mode of being motivated when she starts helping others by pointing: not out of cognitively demanding mediate or instrumental motives, but immediately or intrinsically simply by being moved by the 'claim' of the other's need and/or will on oneself (when the child is capable of having a rudimentary cognitive grasp of these of course). This is to suggest that perhaps intrinsic motivational altruism is (at least part of) the explanation for why communicative pointing apparently "comes naturally" to infants, ${ }^{20}$ whereas other currently existing animals never engage in it.

In whatever way it has come about, and whatever are the requirements for its reproduction, perhaps the human capacity for recognitive attitudes, for being immediately motivated by others, simplifies things between humans, unburdens their interaction from excessive cognitive demands, and thereby gives them an advantage thanks to which they are able to make the decisive step into the realm of genuine Gricean communication - first by pointing and later in the even more complex symbolic mode.

In other words, perhaps the recognitive attitudes of respect and love are what gets the normal members of one

\footnotetext{
${ }^{19}$ Note that we are not dealing with instinct-driven coordination of behavior that may arise without any intersubjective expectations, but about action with a means-end-structure. The point is that if some animals are capable of interaction where they have expectations concerning each other's motives in the first place, then their cognitive task will be significantly easier if they can, at least in some important matters, tacitly rely on the respective others' having intrinsically altruistic motives.

${ }^{20}$ In Tomasello's $(2008,112)$ view, infants do not learn pointing by imitation, but it "comes naturally to them in some way". It would be useful to know whether the child's propensity to help by pointing is affected by 'appealing' or 'commanding' expressions by the other. Also, it would be useful to know whether expectations for rewards or sanctions for helping or not helping by pointing play some role, and if so, which role exactly. Compare Warneken \& Tomasello 2008.
} 
animal species, the human, over their animal motivational solipsism, and, by enabling them to engage in complex forms of communication, emancipates them from cognitive solipsism more generally and thereby launches them into the developmental path normally leading to full-fledged psychological personhood. This of course does not rule out that a more intelligent species of animals could start Gricean communication by orienting in a space of exclusively instrumental reasons. But for the most intelligent currently existing species this may be just too difficult. ${ }^{21}$

\section{Acknowledgements}

I wish to thank participants of the ASCS 2009, as well as participants of the Workgroup on Recognition at Macquarie University, November 17, 2009 for helpful comments and questions. The research was funded by a Macquarie Research Fellowship.

\section{References}

Bates, E., Camaioni, L., Volterra, V. (1975). The acquisition of performatives prior to speech. Merrill-Palmer Quarterly 21: 205-224.

Brandom, Robert (1999). Some Pragmatist Themes in Hegel's Idealism: Negotiation and Administration in Hegel's Account of the Structure and Content of Conceptual Norms, European Journal of Philosophy, Vol. 7, No. 2, 164-189.

Brandom, Robert (2007). 'The structure of desire and recognition: Self-consciousness and self-constitution', Philosophy and Social Criticism, 33, 127-50.

van den Brink, B. \& Owen, D. (Eds.) (2007). Recognition and Power. Cambridge: Cambridge University Press.

Dixon, T. (2005) Altruism. In M. C. Horowitz (Ed.) New Dictionary of the History of Ideas, volume 1. Detroit: Thomson Gale.

Grice, H. P. (1957). Meaning, Philosophical Review LXVI, 377-388.

Hegel, G. W. F. (1978-9 [1830]). Hegel's Philosophy of Subjective Spirit. Edited and translated by M. J. Petry. Dordrecht: Reidel.

Honneth, A. (1995). The Struggle for Recognition - The Moral and Political Grammar of Social Conflicts. Cambridge: Polity Press.

Honneth, A. (2001). Invisibility: On the Epistemology of 'Recognition'. Proceeding of the Aristotelian Society: Supplementary Volume 75, 111-126.

\footnotetext{
${ }^{21}$ An interesting question is whether there are subjects or persons who have deficient capacities for intrinsic altruism compensated by better than usual capacities for recursive mind-reading. This would still be compatible with the possibility that a subject's complete incapacity to intrinsic altruism, i.e. recognition, makes Gricean communication, and therefore all further cognitive, emotional etc. development dependent on it, impossible for the subject. Another question is how much lack of intrinsic altruism in one communicator can be compensated by intrinsic altruism in the other communicators.
}

Honneth, A. (2008). Reification: A New Look at an Old Idea. Oxford: Oxford University Press.

Ikäheimo, H. (2002). On the Genus and Species of Recognition, Inquiry, Vol. 45, No. 4, 447-462.

Ikaheimo, H. (2007). Recognizing Persons. Journal of Consciousness Studies, Vol. 14, No. 5-6, 6-16.

Ikaheimo, H. (2010). Making the Best of What We Are Recognition as an Ethical and Ontological Concept. In H.C. Schmidt am Busch \& C. Zurn (Eds.) The Philosophy of Recognition. Lanham: Lexington Books.

Ikaheimo H. \& Laitinen A. (2007). Analyzing Recognition: Identification, Acknowledgement and Recognitive Attitudes Between Persons. In B. van den Brink \& D. Owen (Eds.) Recognition and Power.

Joyce, R. (2006). The Evolution of Morality. Cambridge MIT press.

Leavens, D. A., Hopkins, W. D., Bard. K. A. (2008). The heterochronic origins of explicit reference. In J. Zlatev, T. P. Racine, C. Sinha \& E. Itkonen (Eds.). The Shared Mind: Perspectives on Intersubjectivity. Amsterdam/Philadelphia: John Benjamins.

Liszkowski, U. (2006). Infant Pointing at 12 Months: communicative Goals, Motives, and Social-Cognitive Abilities. In N. E. Enfield \& C. Levinson (Eds.). Roots of Human Sociality: Culture, Cognition and Interaction. Oxford: Berg.

Moll, H. (2007). Person und Perspektivität. Kooperation und soziale Kognition beim Menschen. In F. Kannetsky \& H. Tegtmeyer (Eds.). Personalität - Studien zu einem Schlüsselbegriff der Philosophie. Leipziger Schriften zur Philosophie 19. Leipzig: Leipziger Universitätsverlag.

Prinz, J. (2007). The Emotional Construction of Morals. Oxford: Oxford University Press.

Schwe, H. \& Markman, E. (1997). Young children's appreciation of the mental impact of their communicative signals. Developmental Psychology, 33, 630-635.

Schmidt am Busch H.-C. \& Zurn C. (Eds.) (forthcoming). The Philosophy of Recognition. Lexington Books.

Siep, Ludwig (1979). Anerkennung als Prinzip der praktischen Philosophie. Freiburg: Karl Alber.

Stekeler-Weithofer, P. (2007). Persons and Practices. Journal of Consciousness Studies, Vol. 14, No. 5-6, 174198.

Stekeler-Weithofer, P. (forthcoming). Intuition and understanding as conditions for being persons. Ikäheimo, H. \& Laitinen, A. (Eds.). Social Ontology and Recognition. Leiden: Brill.

Taylor, Charles (1992). The Politics of Recognition. Amy Guttman (ed.) Multiculturalism and 'The Politics of Recognition'. Princeton, Princeton University Press.

Thompson, S. (2006). The Political Theory of Recognition. Cambridge: Polity Press.

Tomasello, M. (2006). Why don't apes point? In N. E. Enfield \& C. Levinson (Eds.) Roots of Human Sociality: Culture, Cognition and Interaction. Oxford: Berg.

Tomasello, M. (2008). Origins of Human Communication. Cambridge, Massachusetts: MIT Press. 
Warneken, F. \& Tomasello, M. (2008). 'Extrinsic Rewards Undermine Altruistic Tendencies in 20-Month-Olds'. Developmental Psychology, Vol. 44, No. 6, 1785-1788.

Wildt, Andreas (1992). Autonomie und Anerkennung. Stuttgart: Clett-Cotta.

Williams, Robert R. (1992). Recognition - Fichte and Hegel on the Other. Albany: State University of New York Press.

Williams, Robert R. (1997). Hegel's Ethics of Recognition. Berkeley: University of California Press. 